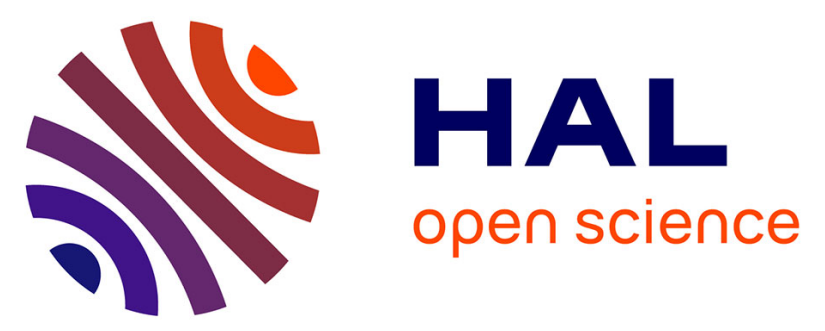

\title{
Changing gears to neutral in a polymorph of one-dimensional arrays of cogwheel-like pairs of molecular rotors
}

Guillaume Bastien, Cyprien Lemouchi, Magali Allain, Pawel Wzietek, Antonio Rodríguez-Fortea, Enric Canadell, Konstantinos Iliopoulos, Denis Gindre, Michel Chrysos, Patrick Batail

\section{To cite this version:}

Guillaume Bastien, Cyprien Lemouchi, Magali Allain, Pawel Wzietek, Antonio Rodríguez-Fortea, et al.. Changing gears to neutral in a polymorph of one-dimensional arrays of cogwheel-like pairs of molecular rotors. CrystEngComm, 2014, 16 (7), pp.1241-1244. 10.1039/c3ce42054j . hal-03344840

\section{HAL Id: hal-03344840 \\ https://univ-angers.hal.science/hal-03344840}

Submitted on 15 Sep 2021

HAL is a multi-disciplinary open access archive for the deposit and dissemination of scientific research documents, whether they are published or not. The documents may come from teaching and research institutions in France or abroad, or from public or private research centers.
L'archive ouverte pluridisciplinaire HAL, est destinée au dépôt et à la diffusion de documents scientifiques de niveau recherche, publiés ou non, émanant des établissements d'enseignement et de recherche français ou étrangers, des laboratoires publics ou privés. 


\section{CrystEngComm}

\section{Accepted Manuscript}

This article can be cited before page numbers have been issued, to do this please use: G. Bastien, C. Lemouchi, M. Allain, P. Wzietek, A. Rodriguez-Fortea, E. Canadell, K. lliopoulos, D. Gindre, M. Chrysos and P. Batail, CrystEngComm, 2013, DOI: 10.1039/C3CE42054J.

\section{CrystEngComm}

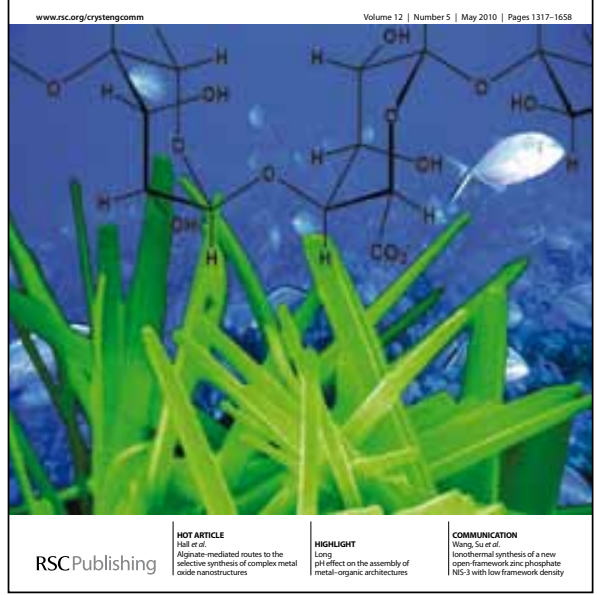

This is an Accepted Manuscript, which has been through the RSC Publishing peer review process and has been accepted for publication.

Accepted Manuscripts are published online shortly after acceptance, which is prior to technical editing, formatting and proof reading. This free service from RSC Publishing allows authors to make their results available to the community, in citable form, before publication of the edited article. This Accepted Manuscript will be replaced by the edited and formatted Advance Article as soon as this is available.

To cite this manuscript please use its permanent Digital Object Identifier $\left.(\mathrm{DO})^{\oplus}\right)$, which is identical for all formats of publication.

More information about Accepted Manuscripts can be found in the Information for Authors.

Please note that technical editing may introduce minor changes to the text and/or graphics contained in the manuscript submitted by the author(s) which may alter content, and that the standard Terms \& Conditions and the ethical guidelines that apply to the journal are still applicable. In no event shall the RSC be held responsible for any errors or omissions in these Accepted Manuscript manuscripts or any consequences arising from the use of any information contained in them. 


\section{CrystEngComm}

\section{COMMUNICATION}

Cite this: DOI: 10.1039/xoxxo0000x

Received ooth January 2012, Accepted ooth January 2012

DOI: 10.1039/xoxxo0ooox

www.rsc.org/

\section{Changing gears to neutral in a polymorph of one- dimensional arrays of cogwheels pairs of molecular rotors}

Guillaume Bastien, ${ }^{a, f}$ Cyprien Lemouchi, ${ }^{a}$ Magali Allain, ${ }^{a}$ Pawel Wzietek, ${ }^{b}$ Antonio Rodríguez-Fortea, ${ }^{c}$ Enric Canadell, ${ }^{d}$ Konstantinos Iliopoulos,${ }^{a, e}$ Denis Gindre, ${ }^{a}$ Michael Chrysos ${ }^{a}$ and Patrick Batail ${ }^{* a}$ 


\section{COMMUNICATION}

We report on a polymorph (2) of an amphidynamic crystal of molecular rods with two helical 1,4bis(ethynyl)bicyclo[2.2.2] octane rotators where half of the rod-like molecules appear to be shifted with respect to their closest neighbours; this translation takes cogwheellike pairs of rotators apart in the lattice in such a way that their motion becomes uncorrelated while keeping with the properties of the former polymorph (1) related to the handedness of the rotors and to 'mutamer'-induced second-harmonic generation.

Applications of molecular machines in materials science and nanotechnologies require in-depth understanding and control of the complex dynamics of their moving parts. ${ }^{1-8}$ An example in this respect is the coupled analysis of variable-temperature ${ }^{1} \mathrm{H}$ spin-lattice relaxation data and rotor-rotor interaction-energy calculations concluding that the rotational motion between neighboring molecules assembled in one-dimensional crystalline arrays (Figure 1a) is correlated: adjacent 1,4bis(ethynyl)bicyclo[2.2.2] octane rotors move so closely as to rub against each other in a pair, just like cogwheels in microscopic clockwork. ${ }^{9}$ Here, we report the discovery and dynamic properties of a polymorph of this system, hereafter referred to as polymorph $\mathbf{2}$ (Chart $\mathrm{S} 1$ ).

In order to probe the anisotropy of the ${ }^{1} \mathrm{H}$ spin-lattice relaxation of this one-dimensional system, we sought to carry out experiments on one single crystal aligned in the magnetic field. Hence, attempts at growing a single crystal larger than those obtained previously were conducted by slow cooling of a refluxing acetonitrile solution of a crystalline sample of the former polymorph 1 (see the supplementary information). Note that crystals of polymorph 1 were typically obtained by a different procedure by which the flask of hot acetonitrile solution was left to cool off out of the oil bath. The present slow crystallization protocol yields thinner, plate-like single crystals of a different habit (Chart S1). The two polymorphs have the same monoclinic system and $C 2 / c$ space group, yet their unit
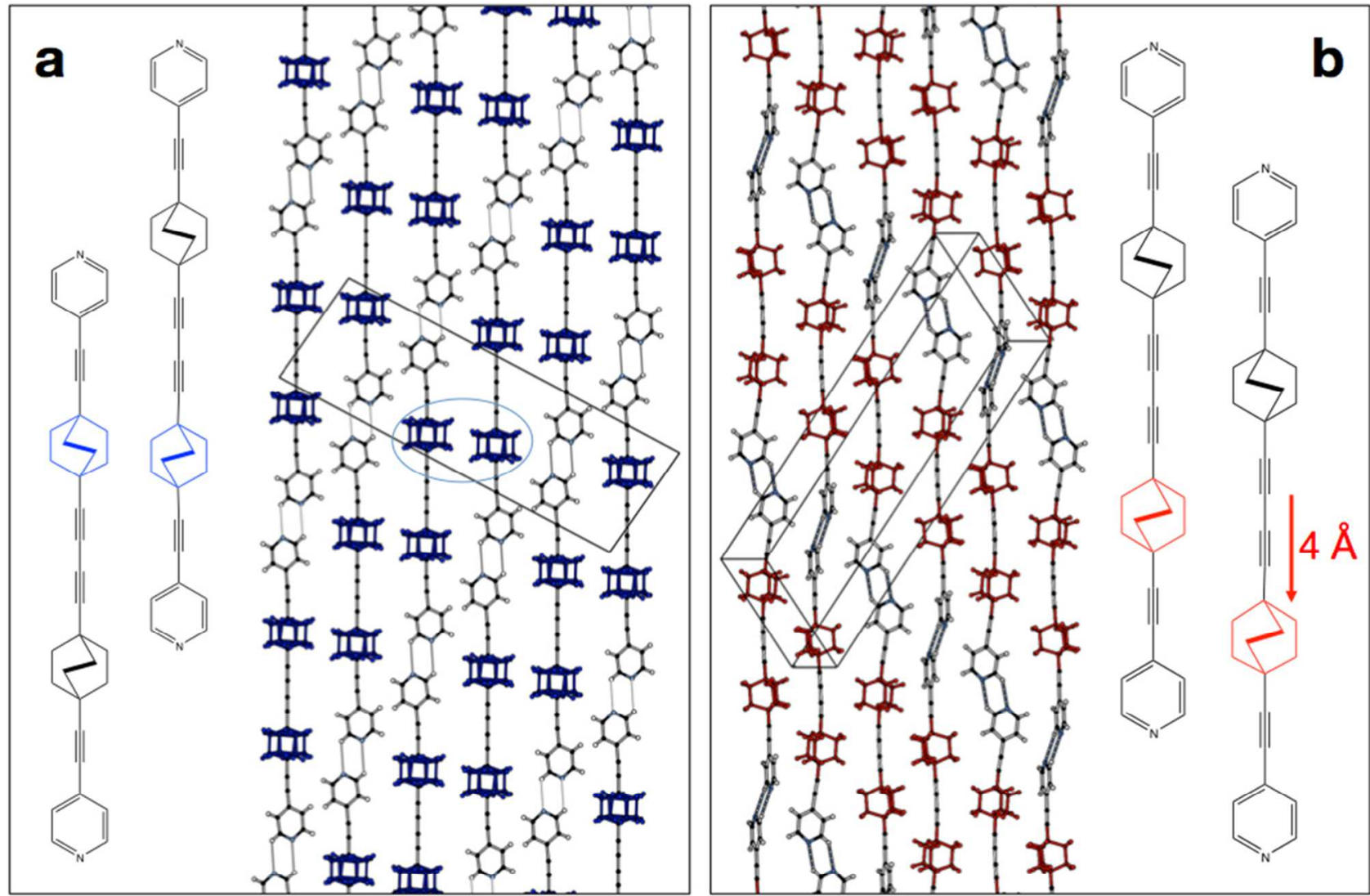

Fig 1. (a) Structure of polymorph 1 with a cogwheel-like pair illustrated inside the blue ellipse, and (b) Structure of polymorph $\mathbf{2}$. The $4 \AA$ A longitudinal shift from $\mathbf{1}$ to $\mathbf{2}$ is accompanied by a rotation of the outer pyridine units whose angle changes from $55.2^{\circ}$ to $33.99^{\circ}$.

cells and structures (see supplementary information) are different: $a=36.831(3)$ [31.539(6)], $b=6.1181(4)$ [8.3673(8)], $c=12.2456(12)[10.2441(9)] \AA, \beta=99.224(7)[97.164(8)]^{\circ}, \mathrm{V}$ $=2723.7(4)[2682.3(6)] \AA^{3} ;$ for polymorphs 2and [1]

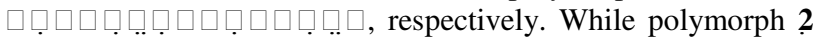
retains the one-dimensional character of a self-assembled structure of parallel $\mathrm{C}-\mathrm{H} \cdots \mathrm{N}$ hydrogen-bonded (Table S1) strings of tetrayne molecules with two rotors (Figure 1), and thereby the unique director of the rotors' axles, the $4 \AA$ translation of every other rotor axle (Figure 1b) that occurs in polymorph 2 suppresses the cogwheel-like pairs of molecular rotors characteristic of the former polymorph $\mathbf{1}$. The translation along the rotors' axle that occurs in polymorph $\mathbf{2}$ is likely to relax the constraints inherent in polymorph $\mathbf{1}$ to the set of $\mathrm{H} \cdots \mathrm{H}$ distances shorter than $2.4 \AA$ because of the close proximity between rotors within a pair (Figure 1a). ${ }^{9}$ Indeed, in the novel, 4 $\AA$ shifted structure, all $\mathrm{H} \cdots \mathrm{H}$ contacts in which the rotors are engaged are larger than $2.53 \AA$. 


\section{CrystEngComm}

The rotational barriers were evaluated by means of density functional theory ${ }^{10}$ (DFT) calculations. They have been estimated exactly as in our previous investigation of polymorph $\mathbf{1},{ }^{8}$ i.e. searching, by means of partial geometry optimizations, for the lowest energy path corresponding to the synchronous and asynchronous motions of a simplified model with two adjacent rotors that have been capped at the two sides. In contrast with our results for $\mathbf{1}$, we found that both barriers are very similar with that for the asynchronous motion being only marginally larger, $1.8 \mathrm{kcal} \mathrm{mol}^{-1}$. Thus we conclude that only one rotational barrier of this order of magnitude should be effectively observed for polymorph $\mathbf{2}$.

Variable temperature $\quad{ }^{1} \mathrm{H} \quad T_{1}$ spin-lattice relaxation experiments $^{2,8,9}$ were conducted at $55 \mathrm{MHz}$ (Figure 2) on a batch of hand-picked diamond-shaped crystals of polymorph 2

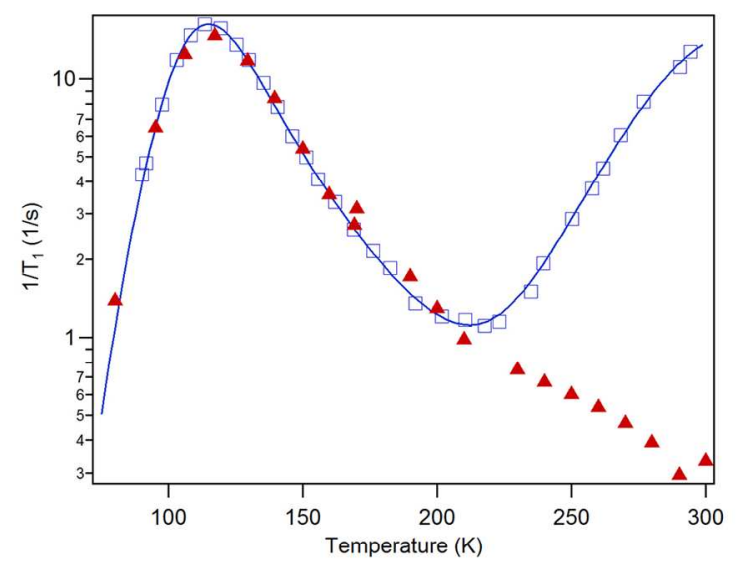

Fig. 2. Variable temperature reciprocal spin-lattice relaxation time at $55 \mathrm{MHz}$ for polymorph $\mathbf{1}$ (blue squares) and polymorph $\mathbf{2}$ (red triangle).

introduced one by one in a capillary (supplementary information). Only one thermally activated relaxation process, with a $T^{-1}$ maximum at ca. $115 \mathrm{~K}$, is observed for polymorph 2 (red triangles in Figure 2). This corroborates the conclusions of the structural and quantum chemistry analysis reported above. Remarkably, the $T^{-1}$ maximum near room temperature associated in polymorph $\mathbf{1}$ to a high energy barrier of $5 \mathrm{kcal}$ $\mathrm{mol}^{-1}$ and assigned to the disruption of the correlated motion in a pair is indeed not present in polymorph $\mathbf{2}$. The occurrence of one $T_{1}^{-1}$ maximum in the whole temperature range is entirely consistent with all rotors in polymorph $\mathbf{2}$ being located far from each other on one single crystallographic site with one equilibrium position only. This is a salient difference with the rotor dynamics in polymer $\mathbf{1}$ where the two $T_{1}^{-1}$ maxima were interpreted as corresponding to the different relative motions between two rotors in a pair. We recall that for the former kinetic polymorph 1 , the $T^{-1}$ maximum at ca. $115 \mathrm{~K}$ (blue squares in Figure 2) was shown to correspond ${ }^{9}$ to an activation energy of $1.85 \mathrm{kcal} \mathrm{mol}^{-1}(930 \mathrm{~K})$ and a pre-exponential factor (or attempt frequency) $\mathrm{A}=1.8210^{12} \mathrm{~s}^{-1}\left(\tau_{0}=5.510^{-13} \mathrm{~s}\right)$. In Figure 2, we show again this fit for comparison. It is clear that the single relaxation process for the thermodynamic polymorph $\mathbf{2}$ corresponds to the low energy process in polymorph $\mathbf{1}$. This result provides direct experimental confirmation that the absence of the $5 \mathrm{kcal} \mathrm{mol}^{-1}$ energy barrier, which had formerly been found (in addition to the low-energy barrier) in polymorph $\mathbf{1}$, lies with the disruption of the highly-correlated motion undergone by the pairs of adjacent rotors in that polymorph.

In order to evaluate further the differences or similarities in the dynamic properties of the two polymorphs, SHG imaging experiments were carried out in a single crystal of polymorph $\mathbf{2}$. SHG is well known for its properties as an effective device to probe the chirality of a material. Although the lattices of the two polymorphs are centrosymmetric and SHG should be expected to be absent, a SHG signal was recorded from 2 in a way analogous to the signal recorded for 1. In Figure 3, the SHG
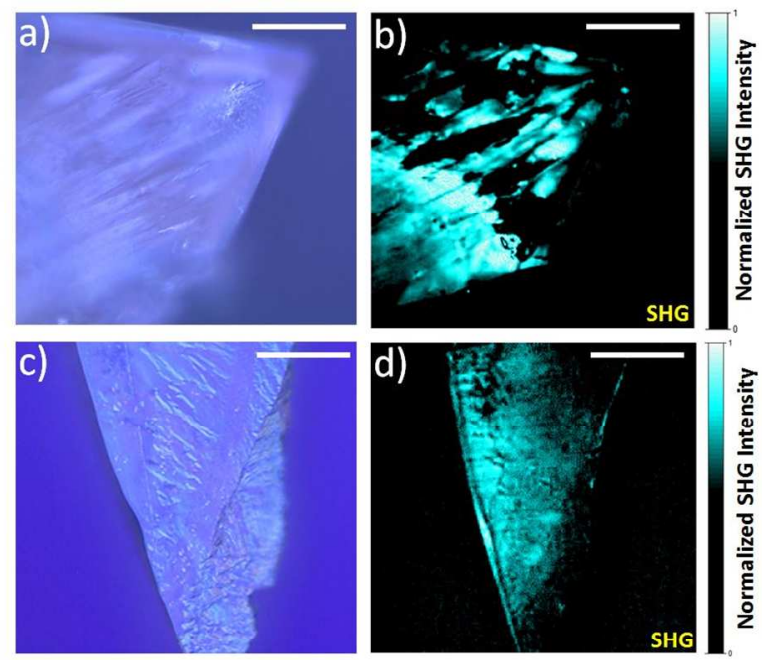

Fig. 3. (a) Optical image and (b) SHG scans of a $145 \mu \mathrm{m}$-thick single crystal of polymorph 1. (c) Optical image and (d) SHG scans of a $25 \mu \mathrm{m}$ thick single crystal of polymorph 2. The scale bar is $100 \mu \mathrm{m}$.

efficiency for both $\mathbf{1}$ and $\mathbf{2}$ is normalized to unity. The efficiency of polymorph $\mathbf{2}$ is ca. 25-30 times lower (depending on the investigated area) because of the difference of thickness of the crystals. Thus, the second-order nonlinearities of polymorphs $\mathbf{1}$ and $\mathbf{2}$ are comparable. As before, this is evidence for a random dynamic conformational switching in the handedness of the rotor helices, which at room temperature can undergo mutations while preserving on the average the spaceinversion symmetry of the lattice. ${ }^{9}$ This result shows that as regards the torsional degree of freedom of the helix blades things keep on in a way similar to the previous material. Only the rotational degree of freedom and the way in which this rotation is correlated between rotators that are close neighbors in the lattice are relevant to the NMR experiment. 


\section{CrystEngComm}

\section{COMMUNICATION}

\section{Conclusions}

Owing to its faster crystallization, the circular, correlated rubbing motion in the rotor-rotor pairs of polymorph 1 shows that a significant amount of $\mathrm{H} \cdots \mathrm{H}$ rotor-rotor interaction energy was stored in the lattice already at the outset. Conversely, in the new polymorph 2, this energy was relaxed adiabatically to a multitude of internal degrees of freedom, as the material cooled down slowly, eventually converging to a less frustrated crystal lattice with the positions of adjacent rotors being repelled far apart. As a result, polymorph 2 is more stable, thermodynamically, than the previous one. Remarkably, upon alternating from the slow to the fast crystallization procedure makes it possible to retransform the structure from $\mathbf{2}$ to $\mathbf{1}$ (Figure $\mathrm{S} 1$ ), and then again to $\mathbf{2}$, as if one was changing gears back and forth from neutral to drive and then back to neutral.

\section{Acknowledgements}

G. B. and C. L. thank the CNRS and the Région des Pays de la Loire for a PhD grant. K. I. acknowledges the Région des Pays de la Loire for a Post-Doctoral grant as well as grant support from the European Commission and General Secretariat for Research and Technology (Greece) for a National Strategic Reference Framework (NSRF) Project (PE3-(1612)). Work at Angers was supported by the CNRS and by the Region des Pays de la Loire Grant MOVAMOL. Work in Bellaterra and Tarragona was supported by the Spanish Ministerio de Economía y Competitividad (Projects FIS2012-37549-C05-05, FIS2009-1271-C04-03, CTQ2011-29054-C02-01 and CSD 2007-00041).

\section{Notes and references}

a Laboratoire MOLTECH-Anjou, Université d'Angers, CNRS UMR 6200, 2 Boulevard Lavoisier, 49045 Angers, France.

${ }^{b}$ Laboratoire de Physique des Solides, Université de Paris-Sud, CNRS UMR 6502, Bâtiment 510, 91405 Orsay, France.

${ }^{c}$ Departament de Química Física i Inorgànica, Universitat Rovira i Virgili, Marcel-lí Domingo s/n, 43007 Tarragona, Spain.

${ }^{d}$ Institut de Ciència de Materials de Barcelona (ICMAB-CSIC), Campus de la UAB, 08193, Bellaterra, Spain.

${ }^{e}$ Institute of Chemical Engineering Sciences (ICE-HT), Foundation for Research and Technology-Hellas (FORTH), P.O. Box 1414, Patras 26504, Greece.

${ }^{f}$ Present address: Institut Néel, 25 avenue des Martyrs, Bâtiment F, BP 166, 38042 Grenoble cedex 9, France.

$\dagger$ Crystal data for polymorph 2: $\mathrm{C}_{34} \mathrm{H}_{32} \mathrm{~N}_{2}, M=468.62$, monoclinic $C 2 / c, 293 \mathrm{~K}, a=36.831(3), b=6.1181(4), c=12.2456(12) \AA, \beta=$ 99.224(7) ${ }^{\circ}, V=2723.7(4) \AA^{3}, Z=4, \mu=0.66 \mathrm{~cm}^{-1}, 2 \Theta_{\max }=54^{\circ}, 22778$ reflections measured, 2941 unique $\left(R_{\text {int }}=0.083\right), 1772$ with $I>2 \sigma(I), 227$ parameters refined, $R\left(F^{2}\right)=0.0590, w R\left(F^{2}\right)=0.1181, \mathrm{GOF}=1.029$.

Electronic Supplementary Information (ESI) available: Crystallization procedures, experimental details and cif file, Chart S1, Figures S1 and S2, and Table S1. See DOI: 10.1039/c000000x/

1 B. Rodríguez-Molina, S. Peŕez-Estrada, and M. A. Garcia-Garibay, M. A. J. Am. Chem. Soc. 2013, 135, 10388; B. Rodríguez-Molina, N.
Farfán, M. Romero, J. M. Méndez-Stivalet, R. Santillan and M. A. Garcia-Garibay, J. Am. Chem. Soc. 2011, 133, 7280. A. Name, B. Name and C. Name, Journal Title, 2000, 35, 3523.

2 M. A. Garcia-Garibay, Proc. Natl. Acad. Sci. 2005, 102, 10771; T.-A. V. Khuong, J. E. Nunez, C. E. Godinez, and M. A. Garcia-Garibay, Acc. Chem. Res. 2006, 39, 413; S. D. Karlen, H. Reyes, R. E. Taylor, S. I. Khan, M. F. Hawthorne and M. A. Garcia-Garibay, Proc. Natl. Acad. Sc. USA 2010, 107, 14973; V. Vogelsberg, M. A. GarciaGaribay, Chem. Soc. Rev. 2012, 41, 1892.

3 W. Setaka and K. Yamaguchi, Proc. Natl. Acad. Sc. USA 2012, 109, 9271; W. Setaka and K. Yamaguchi, J. Am. Chem. Soc. 2012, 134, 17932.

4 W. Zhang and R.-G. Xiong, Chem. Rev. 2012, 112, 1163; W. Zhang, H.-Y. Ye, R. Graf, H. W. Spiess, Y.-F. Yao, R.-Q. Zhu and R.-G. Xiong, J. Am. Chem. Soc. 2013, 135, 5230.

5 S. Horiuchi, Y. Tokunaga, G. Giovanetti, S. Picozzi, H. Itoh, R. Shimano, R. Kumai and Y. Tokura, Nature 2010, 463, 789; T. Akutagawa, H. Koshinaka, D. Sato, S. Takeda, S. I. Noro, H. Takahashi, R. Kumai, Y. Tokura and T. Nakamura, Nat. Mater. 2009, 8, 342 .

6 S. Yamamoto, H. Iida and E. Yashima, Angew. Chem. Int. Ed. 2013, 52, 6849 .

7 Q.-C. Zhang, F.-T. Wu, H.-M. Hao, H. Xu, H.-X. Zhao, L.-S. Long, R.-B. Huang and L.-S. Zheng, Angew. Chem. Intl. Ed. 2013, 52, doi.org/10.1002/anie.201306193.

8 C. Lemouchi, C. Vogelsberg, S. Simonov, L. Zorina, P. Batail, S. Brown and M. A. Garcia-Garibay, J. Am. Chem. Soc. 2011, 133, 6371; Correction: J. Am. Chem. Soc. 2011, 133, 13765; C. Lemouchi, C. Mézière, L. Zorina, S. Simonov, A. Rodríguez-Fortea, E. Canadell, P. Wzietek, P. Auban-Senzier, C. Pasquier, T. Giamarchi, M. A. Garcia-Garibay and P. Batail, J. Am. Chem. Soc. 2012, 134, 7880 .

9 C. Lemouchi, K. Iliopoulos, L. Zorina, S. Simonov, P. Wzietek, T. Cauchy, A. Rodríguez-Fortea, E. Canadell, J. Kaleta, J. Michl, D. Gindre, M. Chrysos and P. Batail, J. Am. Chem. Soc. 2013, 135, 9366.

10 P. Hohenberg and W. Kohn, Phys. Rev. 1964, 136, B864; W. Kohn and L. J. Sham, Phys. Rev. 1965, 140, A1133. 
Polymorph $\mathbf{2}$ is more stable, thermodynamically, than polymorph $\mathbf{1}$. Remarkably, upon alternating from slow to fast crystallization procedure makes it possible to retransform the structure from $\mathbf{2}$ to $\mathbf{1}$, and then again to $\mathbf{2}$, as if one was changing gears back and forth from neutral to drive and then back to neutral.
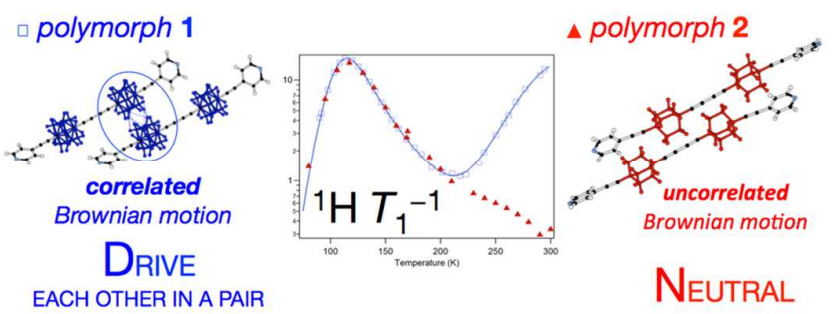

EACH OTHER IN A PAIR

Neutral 